CULTURA, LENGUAJE Y REPRESENTACIÓN / CULTURE, LANGUAGE AND REPRESENTATION · ISSN 1697-7750 • VOL. XXI \2019, pp. 113-132 REVISTA DE ESTUDIOS CULTURALES DE LA UNIVERSITAT JAUME I / CULTURAL STUDIES JOURNAL OF UNIVERSITAT JAUME I DOI: HTTP://DX.DOI.ORG/10.6035/CLR.2019.21.7

\title{
Combates verbales en Twitter. El caso de la expresidenta argentina Fernández de Kirchner en las elecciones legislativas de 2017
}

Verbal combats on Twitter. The case of the former Argentina President Fernández de Kirchner in the parlamentary elections of 2017

RESUMEN: Este artículo analiza un conjunto de interacciones verbales agresivas, publicadas en el microblog Twitter, entre simpatizantes y detractores de la expresidenta argentina Cristina Fernández de Kirchner. El estudio se fundamenta teórica y metodológicamente en el Análisis del discurso con enfoque interpretativo e interdisciplinar. El análisis destaca el reclamo de la victoria del macrismo en las elecciones legislativas de 2017, bajo la lógica de la disputa en los espacios virtuales de interacción. Desmontar los mecanismos retóricos y dialécticos de esas acciones de fuerza permite reflexionar sobre las posibilidades y limitaciones de la participación ciudadana en las redes sociales, así como comprender los sentidos construidos acerca de las victorias en la arena política, en general, y en la coyuntura argentina, en particular.

Palabras clave: (entre 4 y 8 palabras) erística, disputas públicas, redes sociales, izquierda latinoamericana, política argentina.

ABSTRACT: This paper analyzes a set of aggressive verbal interactions, published in the Twitter microblog, between sympathizers and detractors of the Argentine expresident Cristina Fernández de Kirchner. The study is theoretically and methodologically based on discourse analysis with an interpretive and interdisciplinary approach. The analysis highlights the claim of victories in the virtual spaces colonized by the militants. Dismantling the rhetorical and dialectical mechanisms of these forceful actions allows us to reflect on the possibilities and limitations of citizen participation in social networks, as well as to understand the meanings built about the victories in the political arena, in general, and in the Argentinean juncture, in particular.

Keywords: eristics, public disputes, social networks, Latin American left, Argentine politics. 


\section{INTRODUCCIÓN}

El 22 de octubre de 2017, la expresidenta argentina Cristina Fernández de Kirchner fue elegida como senadora del partido Unidad Ciudadana, pero con una votación menor a la obtenida por su principal opositor, del partido oficialista. El presidente Mauricio Macri (electo en diciembre de 2015) abonaba ese resultado a su proyecto antikirchnerista en zonas, incluso, donde mayorías del peronismo habían apoyado al kirchnerismo durante más de una década.

El resultado del pulso entre esas fuerzas políticas en oposición le daba ventajas al Presidente para consolidar su proyecto gubernamental, resuelto en un clivaje configurado durante la campaña y el primer bienio presidencial: consolidar el cambio prometido o volver al pasado como un regreso a la anormalidad, incorporado en la figura de la expresidenta. Esa construcción de una nueva normalidad del país y el cierre de las grietas abiertas por el kirchnerismo, estuvieron en el centro de la comunicación política macrista, con un estilo gerencialista, poco confrontativo pero, al mismo tiempo, sostenido sobre la polarización política como principal fuente de apoyos ciudadanos (Vommaro y Gené, 2017: 251).

Estas elecciones, además, representaban el banderazo inicial hacia la próxima carrera presidencial, donde se definiría el regreso al poder presidencial de las fuerzas progresistas y de izquierda o la continuidad de las llamadas «políticas pragmáticas y postideológicas» (Malamud, 2016a: 27). A nivel geopolítico, las elecciones también resultaban coyunturales para los países de la región, en un escenario de desgaste y retroceso de la izquierda latinoamericana después de su ascenso coincidente en algunos países desde principios de este siglo. A nivel de la ciudadanía, la tensión entre estos proyectos de poder y la presión ejercida para lograr su apoyo, polarizaron el espectro social en el país alrededor de las victorias declaradas en cada bando.

Este artículo se interesa por esa coyuntura política, para analizar las demostraciones de fuerza desplegadas por los militantes del kirchnerismo y del oficialismo como reacciones al discurso emitido públicamente por la expresidenta en la noche de ese 22 de octubre. Esas acciones de fuerza quedaron registradas en el microblog Twitter, a través de los comentarios o tuits de simpatizantes y detractores.

\subsection{TWITTER COMO ARENA}

Desde su aparición, en 2006, Twitter ha llamado la atención de las áreas relacionadas con la comunicación política, por conjugar las características funcionales de las redes sociales, la mensajería instantánea y la publicación o replicación libre de textos breves en formatos múltiples y de enlaces a contenido vinculado en línea. Ahora, esta aplicación web gratuita funciona como un microblog con una producción constante y enorme de tuits, en los cuales los investigadores se interesan con objetivos muy diversos, como evaluar campañas electorales, perfilar a sus usuarios y sus filiaciones ideológicas, mapear los tipos y modos de intercambios entre ellos, predecir decisiones políticas, analizar la organización de movilizaciones sociales, estudiar las formas de hibridación entre esta plataforma y otros medios, etc. (Campos-Domínguez, 2017: 787-788). Este panorama es igual de amplio a nivel metodológico, aunque se puede notar una mayor presencia de trabajos cuantitativos a partir de datos masivos (big data) y de algoritmos de tráfico y enlace.

El interés particular en este microblog reside en concebirlo como una arena donde acontecen interacciones erísticas (Jackiewicz, 2016, 2017; Olave, 2019). En cuanto tal, este artículo presenta a los usuarios como contendientes y a sus comentarios, como 
acciones de fuerza dentro de coyunturas políticas externas que las motivan, sostienen y conducen. Así, no se traducirán los tuits como argumentos que conformarían debates políticos más o menos razonados (es decir, no se evaluará la argumentación desde ningún criterio), sino que serán enmarcados enteramente dentro de la analogía de los movimientos de ataque y defensa, propios del combate extraverbal, orientados a partir de lógicas de confrontación subyacentes, de valores reclamados en los líderes políticos confiables y de pasiones movilizadas durante las luchas.

Esta concepción se articula bien con las visiones que coinciden en presentar a Twitter como un «dispositivo de clausura» de las opiniones divergentes (Yasri, 2016: 14), que funciona como una «cámara de eco» (Calvo, 2015: 14) con escaso cruce significativo de ideologías contrarias (Himelboim, McCreery \& Smith, 2013: 78), dado que el sistema mismo está orientado a que los tuiteros reciban en sus perfiles información que coincide con sus juicios, gustos y filiaciones (Calvo, 2015: 16).

\section{METODOLOGÍA}

Entre los días 22 y 24 de octubre de 2017, apareció un total de 208 comentarios $^{1}$ en la cuenta@UniCiudadanaAR del microblog Twitter, como reacción a un video publicado el 22 de octubre, con el título En VIVO Cristina desde el búnker de Unidad Ciudadana.

A partir de los tuits publicados debajo de ese video, se conformó un corpus con aquellos que involucraban agresiones o formas hostiles de reacción/interacción. Se clasificó ese corpus en dos grupos, bajo el criterio de su destinación (a quién se menciona en la línea en respuesta $a$, que proporciona la plataforma): aquellos tuits dirigidos exclusivamente a@UniCiudadanaAR, a @CFKArgentina o a ambas cuentas, comentarios a los cuales se les denomina aquí embates; y aquellos tuits involucrados en interacciones en las cuales pueden aparecer las cuentas anteriores, pero no solo ellas, a los se denominan duelos. En la Tabla 1 se caracterizan estas dos formas de intervención:

Tabla 1. Embates y duelos digitales

\begin{tabular}{ll}
\hline \multicolumn{1}{c}{ Embates } & \multicolumn{1}{c}{ Duelos } \\
\hline Reacciones / interpelaciones & Interacciones / intercambios \\
$\begin{array}{l}\text { Dirigido a uno o más usuarios, } \\
\text { exclusivamente }\end{array}$ & $\begin{array}{l}\text { Sostenidos con cualquier usuario, sin } \\
\text { exclusividad }\end{array}$ \\
Sin respuesta del interlocutor & $\begin{array}{l}\text { Con respuesta(s) del (de los) } \\
\text { interlocutor(es) }\end{array}$
\end{tabular}

Ataque impetuoso e impredecible, que no involucra defensa

Enfrentamiento impetuoso que implica el par ataque/defensa

Unidades conclusivas de significado

Unidades no conclusivas de significado

Relación asimétrica con ventaja del atacado

Relación simétrica entre atacantes y atacados

\footnotetext{
1 Se puede acceder libremente a este hilo de comentarios, en el enlace: https://twitter.com/UniCiudadanaAR/status/922286430373650433
} 
Los tuits pueden aparecer como unidades monomodales o multimodales, tanto en los embates como en los duelos. Para el análisis, se tendrán en cuenta ambos tipos de unidades, pero con hincapié en la función que cumplen en la construcción de relaciones erísticas, más que en la descripción formal de sus componentes. Tampoco se utiliza ninguna taxonomía previa en particular, para la clasificación tipológica de esos recursos. Asimismo, no se tendrá en cuenta el juego con las identidades semióticas en los nicknames ni las imágenes de los perfiles en las cuentas de los usuarios.

Se propone abordar los tuits que conforman este corpus como discursos erísticos, desde una perspectiva interpretativa interdisciplinar. Este enfoque consiste en una práctica analítica que relaciona materiales textuales naturales con saberes referidos al campo en que han sido producidos (Arnoux, 2006: 14). El ejercicio se centra en la búsqueda de las lógicas que subyacen a la aparición de los tuits y a su dimensión erística, a partir de las funciones retóricas y dialécticas de los recursos movilizados en la materialidad textual, para el caso político particular que es objeto de análisis.

El corpus no fue transcrito sino procesado a través de capturas de imagen, para conservar el entorno visual de la plataforma y las características paraverbales y extraverbales de los tuits en el momento de su publicación. En el archivo de trabajo, entonces, cada tuit es una imagen, un gif o un video; su conjunto fue sistematizado en el software Atlas. Ti 1.6.0(484), desde donde se codificaron los datos y se construyeron categorías inductivas emergentes.

Los resultados del análisis se sintetizan más adelante, en la Tabla 2, y se despliegan a través de ejemplos en el resto de la sección subtitulada a continuación. Posteriormente, el texto concluye de manera parcial con una sección de cierre que recapitula, discute y proyecta el ejercicio hacia la continuidad de este tipo de análisis.

\section{RESULTADOS}

\subsection{CARACTERÍSTICAS DISCURSIVAS EN LOS TUITS ANALIZADOS}

La declaración audiovisual de la expresidenta Fernández de Kirchner frente al resultado de las elecciones legislativas de 2017 suscitó un conjunto amplio de agresiones directas contra@UniCiudadanaAR y@CFKArgentina, así como de interacciones virulentas entre los tuiteros simpatizantes y detractores de la candidata al parlamento. Distinguir la destinación de las agresiones ordena el análisis de las movidas retóricas y dialécticas en tanto que embates y duelos que configuran el combate entre los participantes. Embates y duelos virtuales se caracterizan por su escaso nivel de elaboración y una mayor apariencia de improvisación, espontaneidad o acción refleja. Se trata de golpes impetuosos y desafiantes, en cuya impulsividad e impredictibilidad reside su principal capacidad de daño; el carácter apasionado y vehemente de estas acciones no las hace menos efectivas. Defiendo aquí que su abordaje en el marco racional de las estrategias discursivas o en el enfoque político de las ágoras virtuales subestima la centralidad de las acciones irreflexivas, febriles y exaltadas que emergen en los microblogs como huellas del dominio de las emociones en la inserción pública de la voz ciudadana. Constituidos por golpes impetuosos y por interacciones agonísticas, embates y duelos ceden a los imperativos de un tipo de combate indeliberado sin cuerpos; una lucha en la que ganar y perder tiene otras condiciones y sus victorias, premios con formas distintas. 
En el caso particular, el triunfo está representado por la provocación y conducción de un sentimiento de vergüenza pública del político y de sus simpatizantes. Es una vergüenza reclamada intensamente por sus detractores, sobre la base de no haber podido superar en votos al candidato del partido oficialista en las elecciones legislativas nacionales. Ese resultado cuantitativo (41,37\% contra 37,25\%, según la DNE, 2017) fue reconstruido erísticamente por cada actor en confrontación, como una victoria del oficialismo y una derrota del kirchnerismo, o bien, como la victoria de la conformación de una fuerza opositora al gobierno del presidente Macri. La vergüenza política reclamada en los embates y los duelos exigía el reconocimiento de la derrota en las elecciones, a raíz de su omisión en la alocución audiovisual de la expresidenta.

Las diferencias en las destinaciones permiten hablar por separado de embates y de duelos en este caso, pero no son determinantes para la explicación de los objetivos, recursos y efectos de estas acciones. Las movidas aparecen como acciones compartidas, tanto en las reacciones contra las cuentas oficiales de la candidata (embates) como en las interacciones entre los militantes (duelos). En la Tabla 2 se sintetizan estas acciones:

Tabla 2. Embates y duelos en Twitter

\begin{tabular}{lcr}
\hline \multicolumn{3}{c}{ EMBATES Y DUELOS EN TWITTER } \\
\hline $\begin{array}{l}\text { Recurso } \\
(\text { ¿con qué?) }\end{array}$ & $\begin{array}{c}\text { Objetivo } \\
(\text { ¿contra qué?) }\end{array}$ & $\begin{array}{r}\text { Efecto } \\
\text { (¿pasión movilizada?) }\end{array}$ \\
\hline AGRESIÓN & REPUTACIÓN & VERGÜENZA \\
\hline $\begin{array}{l}\text { Denuncia } \\
\text { Insulto }\end{array}$ & $\begin{array}{c}\text { Honestidad } \\
\text { Dignidad }\end{array}$ & $\begin{array}{r}\text { Sospecha } \\
\text { Indignación }\end{array}$ \\
\hline (+) Agonisticus & $(-)$ Fides & (-) Auctóritas \\
\hline Logos & Ethos & Pathos \\
\hline
\end{tabular}

La Tabla organiza el tipo de recurso utilizado por los internautas en ambas formas de disputa virtual (embates y duelos). Cada uno de ellos apunta contra un objetivo específico y espera movilizar unas pasiones específicas en el nivel público.

En la primera columna, la lógica de las agresiones agrupa la variedad de los recursos en una función general de ataque más o menos directo; en la segunda columna, los diferentes objetivos apuntan contra la reputación o prestigio del contradictor; y en el tercera columna, la capacidad de provocar la vergüenza pública de los opositores da cuenta de las variaciones en los efectos de sospecha e indignación que se busca movilizar entre los lectores de los tuits. Agresión, reputación y vergüenza se enlazan, además, en un orden de continuidad que puede leerse como sigue: Las agresiones contra la reputación mueven hacia el avergonzamiento público de los atacados en las arenas donde luchan los internautas. El impacto de estas acciones produce principalmente la profundización de la lucha (+ agonísticus), el agrietamiento de la confianza (- fides) y la puesta en riesgo de la autoridad (- auctóritas). Estas acciones de fuerza pueden inscribirse en el campo de las pruebas por el logos, por el ethos y por el pathos, respectivamente, siguiendo la retórica aristotélica.

Los aspectos sociopolíticos sobre los cuales impactan en mayor medida los embates y los duelos virtuales (+ agonísticus, - fides y - auctóritas) no se presentan como un factor causal de polarización social, sino de radicalización de posicionamientos políticos anteriores. En este corpus, la evidencia lingüística reenvía a representaciones previas sobre la política argentina que obliga a reparar información más bien densa en ese campo y que, por tanto, obtura la entrada de internautas desprevenidos o con datos 
insuficientes para participar en las luchas. Asimismo, las intervenciones muestran afiliaciones partidarias fuertes que no están orientadas a captar nuevos adeptos ni invitan a la discusión pública sobre programas políticos, sino más a la reiteración de eslóganes, a la defensa de posiciones rígidas y al ataque de todo ruido que interfiera en la reproducción de esos ecos.

Esto es importante para poner en cuestión la visión de los microblogs como «nuevas ágoras públicas», «nuevas comunidades imaginadas» (Lutz \& du Toit, 2014) o espacios de debate de las democracias ampliadas. En el nivel del logos, las recursos de las agresiones virtuales radicalizan los posicionamientos políticos previos al profundizar la relación agonistı̌ca ( $\dot{\alpha} \gamma \omega v \imath \sigma \tau \iota \kappa \eta ́)$, en tanto que lucha, pero también en el sentido de la victoria que está anudado en los términos griego y romano (y que en español es opaco). Aun siendo impetuosas, estas agresiones no son meramente instintivas, sino erísticas en cuanto a su inclinación a la victoria o a la posibilidad de declarar que se ha vencido al adversario.

La radicalización de las posturas vía el ethos ataca directamente la reputación del sujeto político (del líder y de sus simpatizantes) a través de la erosión de la fides. El concepto romano aquí (y su análogo en griego, $\pi i \sigma \tau \iota \varsigma$ ) permite dimensionar la direccionalidad de ese ataque, que se dirige más decididamente contra la relación recíproca o el valor compartido de una confianza mutua, que contra el sentimiento unilateral de fe en el otro o en lo otro (Ramírez Vidal, 2018: 39). Este sentido permite entender la aparición de la fides en los embates y duelos virtuales como un intento de quebrantar el pacto de creencia y de lealtad alcanzado entre el líder político y sus militantes.

Por último, la conducción del sentimiento de vergüenza pública radicaliza la amenaza contra la auctóritas, en el orden de las pasiones que los contendientes esperan movilizar en los auditorios adversos. Estos últimos son plurales y complejos, no solo por la multidestinación que permiten las herramientas de la plataforma (mención y contestación individual y múltiple, retuiteo y tendencia o hashtag), sino también porque sus miembros no son homogéneos, no constituyen un auditorio universal y asumen un rol activo en el proceso de persuasión. Así como la fides puede ser solicitada por el orador, pero no se la puede otorgar él mismo, la auctóritas también debe provenir del exterior de quien habla - de los auditorios - y, asimismo, puede ser dañada desde afuera por su fragilidad en el escenario político.

El daño causado por la vergüenza pública consiste en la puesta en cuestión del sentido ejemplarizante de la auctóritas. No solo es un problema de amenaza a la reputación, sino que vía el avergonzamiento avanza hacia la desautorización de aquel que guía o que se presenta como modelo (especialmente, moral) de los demás. En español se ha diluido ese sentido más tutelar al traducir como autoridad un término que no se limita a sus acepciones legales en el derecho, área de influencia que ha sobrecargado ese significado alrededor de la cuestión de la legitimidad del poder ejercido a partir del prestigio que lo autoriza. En un sentido más político, presente en las huellas etimológicas (Campanini y Carboni, 1995: 125; Banchi y Lelli, 1997:139, entre otros), la Auctóritas poseída por el tutor permite que su aprendiz quiera imitarlo por voluntad propia; este carácter de quien guía a través del ejemplo parecía tener además un fuerte reconocimiento social de índole moral, pero también institucional en el marco de la formación del ciudadano en Roma.

Aristóteles introduce la vergüenza (aischýné) como una de las pasiones persuasivas en la Retórica. Como ya lo ha observado la bibliografía sobre el autor (Gil, 2013: 11; Racionero, 1999: 342, nota 88), su interés por la vergüenza radica en la dimensión pública y en los efectos persuasivos que puede lograr su conducción, para la 
construcción o el mantenimiento de la fides política, así como para sus efectos contrarios a través del avergonzamiento. Luego de asociar la vergüenza al riesgo de ser visto (en los ojos está el pudor, 1384a: 34), en diferentes pasajes de la Retórica Aristóteles sugiere que quienes son más susceptibles de ser avergonzados son precisamente las figuras públicas que gozan de auctóritas, en el sentido de su conducta ejemplar: «[están más expuestos a sentir vergüenza] los que nunca han fallado en nada, ya que éstos están en una actitud semejante a la de aquellos que son objeto de admiración» (1384b: 11-12). De ahí que el autor oriente la definición de vergüenza hacia una pérdida de reputación cuya gravedad radica en la mirada sancionatoria de los otros; la persuasión es capaz de producir la vergüenza para poner al descubierto los actos morales reprochables de una autoridad en las arenas públicas. Interesa aquí la dimensión política del acto de avergonzar para erosionar la auctóritas; ese acto, apunta el mismo Aristóteles, se basa en una phantasía, una imagen de pérdida de prestigio que es movilizada en los auditorios: «la vergüenza es una fantasía que concierne a la pérdida de reputación» (1384a: 22).

La lógica de la radicalización conecta, en clave de su dinámica política, los objetivos, los recursos y los efectos de los embates y los duelos virtuales. Esa conexión me permitirá analizar relacionalmente la inscripción verbal y extraverbal de la dimensión erística en esas interacciones, lo cual significa poner en primer plano los modos en que se conectan el ataque a la reputación (vía el ethos), los instrumentos de la agresión verbal (vía el logos) y la conducción de la vergüenza pública (vía el pathos), dentro de la construcción de una cierta lógica de procedimientos, tanto retóricos como dialécticos, en el espacio del microblog en cuestión.

Ahora bien, el uso que doy al término radicalización toma distancia en algunos aspectos del sentido que viene adquiriendo en tendencias emergentes, especialmente en los estudios sobre violencia política y seguridad pública (por ejemplo: Alimi, Demetriou y Bosi, 2015; Borum, 2011; Richards, 2017), en los cuales el término resulta casi indesligable del fenómeno del terrorismo global y del análisis de los grupos llamados extremistas. En algunas de esas perspectivas, además, las nociones de radicalización y de polarización son prácticamente intercambiables, con lo cual no se recaba en la diferencia entre procesos de agrupamiento o alineación (movimientos de desplazamiento) y procesos de profundización de posicionamientos políticos (movimientos de enraizamiento). En otros casos (como en Alimi et al., 2015), la radicalización implica violencia armada o daño físico de facto, y lleva a analizar los procesos en los cuales los movimientos sociales organizados transforman sus acciones no violentas en violentas, o bien, logran frenar (Non-Radicalization) o mitigar (De-Radicalization) de modos variados ese paso hacia la violencia física.

En este texto se comparte, sin embargo, que la radicalización puede aparecer aunque no únicamente - como síntoma, plan o fase inicial de la violencia física (Alimi et al., 2015). El deseo de pasar a la agresión corporal, la premeditación de esas formas de violencia, o bien, la etapa previa al paso hacia ellas, dan cuenta de sentidos de la radicalización que llevan a examinar las coyunturas y los discursos en las cuales aparece como propensión a la violencia o como agresión física potencial. Esto guarda diferencias con la polarización social inscrita en el discurso, que puede funcionar más como un dique de contención y un modo de coexistencia en el disenso (Amossy, 2014: 227-228).

La radicalización, en cambio, asegura la permanencia del disenso ya no por vía de la aceptación de la coexistencia, sino de la resistencia al imperativo de vivir juntos; esto es, a la inevitable confrontación con la diferencia. La participación en microblogs es precisamente un modo de sustraerse del debate y atrincherarse en las opiniones homogéneas, aun cuando los internautas puedan declarar exactamente lo contrario, bajo imposturas democráticas y argumentativas. Ellos preferirían no coexistir en el disenso 
sino en la unanimidad, incluso si esto implica expulsar agresivamente las divergencias del espacio virtual colonizado.

En la lógica de la radicalización, los sujetos se conducen espontáneamente como tropas para defender esas opiniones unánimes, especialmente cuando sus espacios virtuales colonizados son invadidos por los enemigos, a través de embates o de duelos. Los ataques y las defensas generadas a partir de estas escaramuzas profundizan las posturas y los agrupamientos previos a los encuentros, y en el mismo sentido, las hacen más herméticas. Las movidas de enraizamiento aíslan y sectarizan a los sujetos, al contraer (juntar más estrechamente) sus opiniones; se propone aquí que el análisis de esas contracciones en los endogrupos ayuda a la comprensión de las disputas públicas, toda vez que transparentan las lógicas que orientan las dinámicas de radicalización de los usuarios de las plataformas virtuales, en general, y del microblog Twitter, en particular.

En la siguientes secciones, reuniré las variaciones discursivas encontradas en el corpus de tuits construido, en cuatro grupos que llamaré movimientos de ataque, cada uno conformado por el objetivo de la movida, el recurso utilizado y los efectos sociales esperados, presentes además en los dos tipos de destinación directa de los golpes: los embates y los duelos. Los movimientos de ataque serán presentados a través de una selección de ejemplos donde se despliega el contenido de la lógica de la radicalización que ya fue explicada en párrafos anteriores, resumida en la proposición Las agresiones contra la reputación mueven hacia el avergonzamiento público, y que funciona como hipótesis interpretativa de los textos analizados:

3.2. El ATAQUe A LA hONESTIDAD, A tRAVÉS DE LA DENUNCIA, PARA MOVILIZAR SOSPECHAS

\subsubsection{Embates}

Los comentarios dirigidos a @UniCiudadanaAR y@CFKArgentina introdujeron imputaciones contra la expresidenta que denunciaban su deshonestidad o su vileza en el ejercicio de poder. Sobresale la acusación directa de robo, aunque sin ningún tipo de esfuerzo probatorio; el espacio virtual así parece admitirlo, sin perjuicio de reclamo por parte de la imputada. Estas imputaciones son formuladas como interpelaciones vehementes que no responden ni hacen referencia al contenido del mensaje emitido por la expresidenta, sino que gestionan su desactivación a través de la incriminación directa. Los embates son, pues, análogos a la situación oral en la que la tribuna rechaza las palabras del orador al impugnar su honorabilidad:

Figura 1. Embate 1

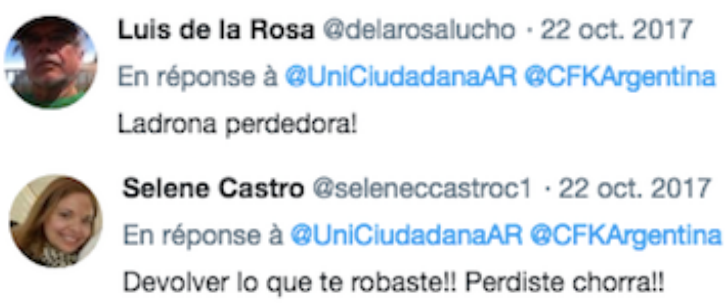

Las acusaciones de los usuarios recogen la difusión mediática de los procesos judiciales adelantados contra la expresidenta, la mayoría de ellos relacionados con manejos ilícitos de dineros públicos (cohecho, malversación, enriquecimiento ilícito, 
lavado y uso de paraísos fiscales) (CNN, 2018, noviembre 9). Pero las imputaciones movilizadas funcionan aquí más como imperativos de silenciamiento del otro (mandarlo a callar) y como efectos esperados en la matriz de opinión de las redes virtuales, que como acusaciones judiciales basadas en las causas legales o restringidas por ellas. Con ello, se entiende que las incriminaciones virtuales, a pesar de estar reguladas por la ley en la mayoría de países (Boix, 2016), suelen pasar desapercibidas cuando la relación entre el injuriado y el injurioso se basa en la transgresión del contrato de poder entre el gobernante y el gobernado, o bien, cuando la identidad de estos últimos queda oculta tras los seudónimos:

\section{Figura 2. Embate 2}

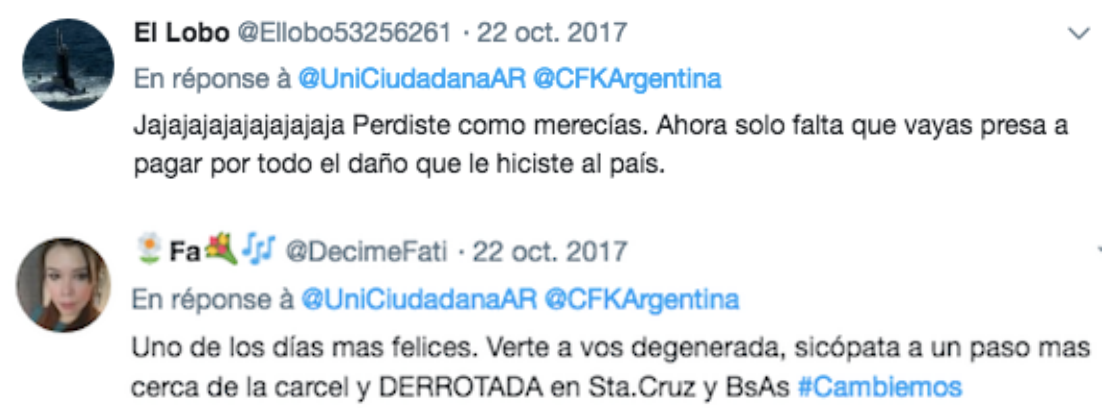

En casos como los ilustrados, las incriminaciones construidas en esas interpelaciones perfiladas oralmente, desde la cuenta personal de Twitter usada como tribuna, aparecen matizadas por la conducción en la opinión pública de una cierta inminencia del castigo de los acusados, esto es, el anuncio del presidio sobre la certeza de la culpabilidad de la expresidenta. Así, ser ladrona, perder las elecciones e ir presa, pasado (imputación), presente (circunstancia) y futuro (amenaza), quedan encadenadas en una línea causal de condiciones y acciones atravesadas por el sentido de justicia: la derrota electoral forma parte del castigo social y anuncia la irrefrenable pena judicial. Al embate se añaden elementos menores que refuerzan esa causalidad construida, como la expresión inicial del entusiasmo (onomatopeya de la risa y declaración superlativa de la felicidad) por los resultados de las elecciones.

A partir del énfasis en el perder, dentro de la contienda democrática, se traslada la victoria electoral a la virtual en forma de derrota merecida (perdiste como merecías). Se reconvierte entonces la imagen previa de la expresidenta y la fides construida con sus simpatizantes en imagen negativa y en una reputación puesta en entredicho. Desde esta lógica, el ataque contra la honestidad es tan efectivo cuanto más explícita sea la imputación; el recurso a la imagen tendrá importancia en ese sentido del «mostrar la evidencia» del crimen, aun cuando quede envuelto en el juego irónico del bricolaje digital (Deuze, 2006; Maireder \& Ausserhofer, 2014), que combina lo verbal y lo gráfico: 
Figura 3. Embate 3

marcela gonzalez @AkdMgonzalež · 24 oct. 2017

En réponse à @UniCludadanaAR @CFKArgentina

Así ganó la Porota pero igual se la comió el Gato êt ê

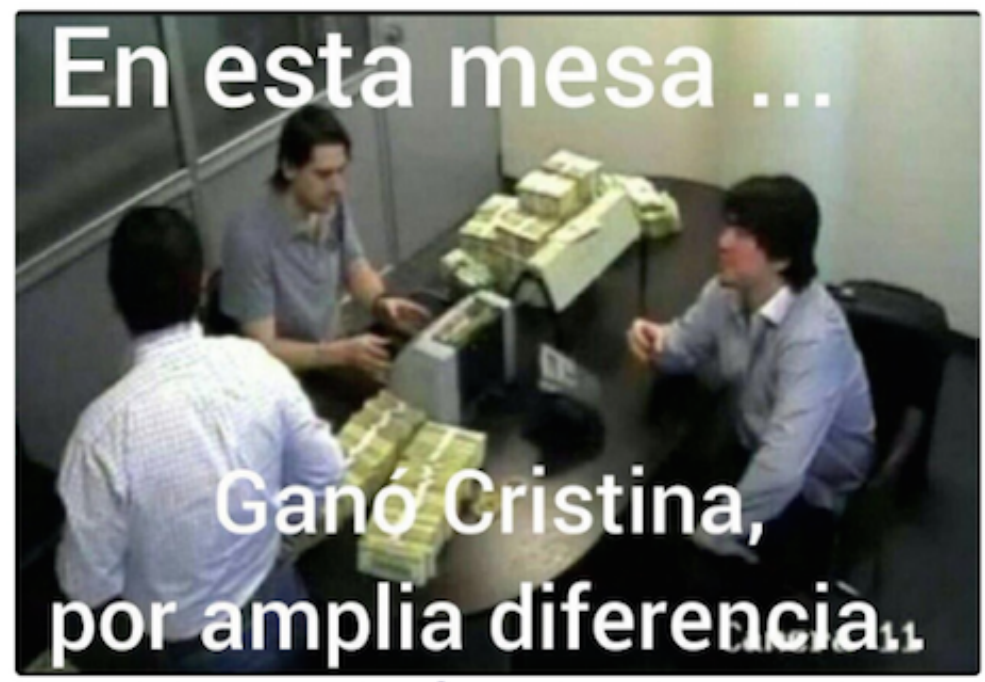

La imagen reciclaba un escándalo de lavado de dineros aparecido en 2012, a través de los videos de una cámara de seguridad en unas oficinas secretas destinadas para ese ilícito. El video comprometió a empresarios cercanos a la familia Kirchner y fue una pieza probatoria en la condena de los imputados directos, por blanqueo de capitales (Farah, 2014, mayo 5). La imagen pasó a formar parte de la militancia contra los gobiernos kirchneristas, bajo la sospecha de tramas de corrupción extendidas a lo largo de sus periodos presidenciales. El reconocimiento de la imagen, por su amplia y repetida difusión en los medios argentinos, fue aprovechado en este tuit para hacer más efectivo el embate desde el sarcasmo contra la honestidad de la expresidenta.

En todos los casos ilustrados, la relación establecida entre la derrota y la deshonestidad es evidentemente estrecha. La copresencia de los términos asociados a ambas ideas (ganar/perder y robo/cárcel) construye la correferencialidad entre ser vencido y ser ladrón, en clave de sentencia por los crímenes imputados.

\subsubsection{Duelos}

En el ámbito de estas interacciones, las disputas se concentran en la defensa o el ataque de la expresidenta bajo la lógica de la militancia política. Se lucha, pues, por o contra el honor del líder y la individualidad de los usuarios queda desplazada; la predominancia de la voz pronominal colectiva y de las acciones programáticas, volcadas hacia el futuro, son huellas de esas motivaciones políticas que hacen aparecer los duelos en el microblog:

Figura 4. Duelo 1 


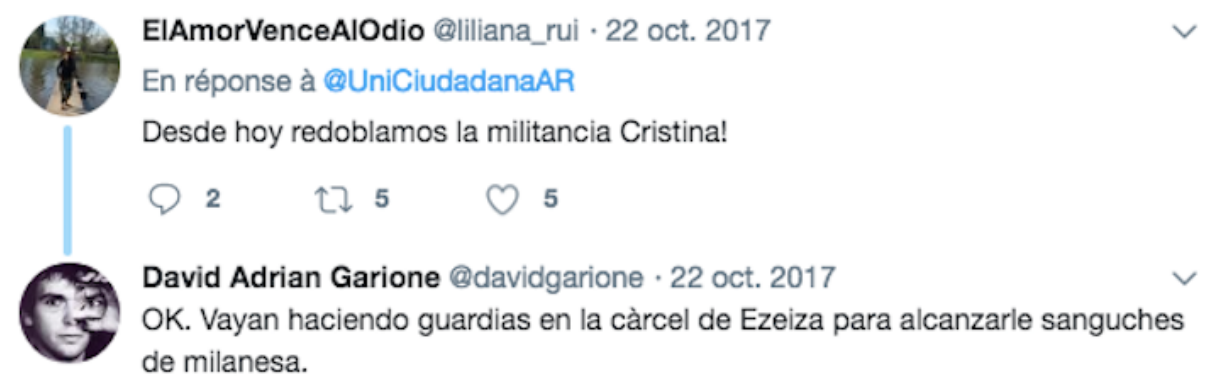

La reacción contra @liliana_rui activa, de nuevo vía el sarcasmo, la cadena causal derrota electora-castigo judicial construida por los contradictores de la expresidenta. En estos casos, los duelos son iniciados como provocaciones a los simpatizantes a partir de sus comentarios solidarios dirigidos al líder de su colectivo; se trata aquí de intromisiones agresivas en la interacción dentro de los endogrupos, que dinamita sus relaciones de fides y auctóritas ganadas por fuera de las escaramuzas virtuales. Estos movimientos invasivos apuestan por la agresión inesperada sobre la base de que el golpe por sorpresa, en el propio territorio del enemigo, aprovecha la ausencia de defensa y genera un daño principalmente moral, según los principios clásicos del combate. Ese daño consiste en su capacidad de «desatar violentamente el vínculo de unión» (Clausewitz, 2005[1832]: 321) en el colectivo del adversario, es decir, erosionar la cohesión del grupo y desalentar a sus militantes por medio de la intimidación.

En otros casos, los duelos pasan de la provocación al contrapunteo cuando encadenan las reacciones entre los usuarios enfrentados:

Figura 5. Duelo 2

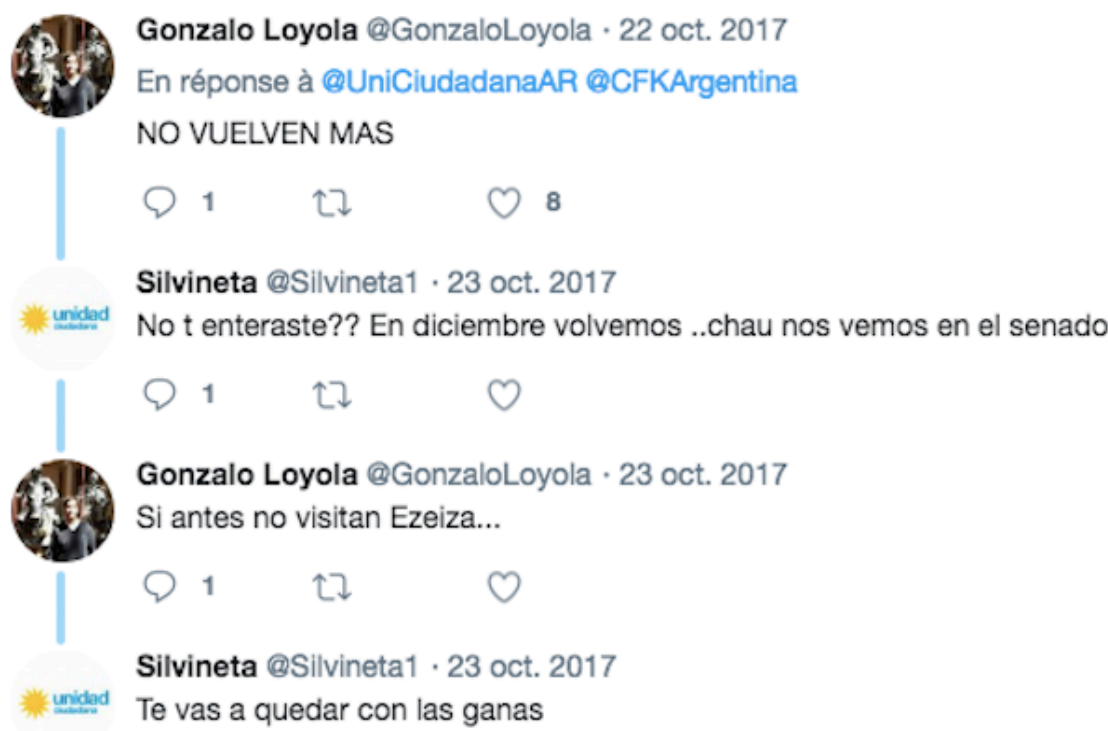

En el ejemplo, el duelo es iniciado por un contradictor que dirige su ataque a las cuentas oficiales de la expresidenta, a través del eslogan No vuelven más, amplificado paraverbalmente. La referencia de la aserción es a los gobiernos kirchneristas, pero también al triunfo alcanzado por el partido oficialista en las votaciones previas, en agosto de 2017, donde los militantes emocionados cantaron la frase que se convertiría en uno de los eslóganes contra el regreso de Fernández de Kirchner al poder. Este recurso se acomoda convenientemente a la restricción de extensión de los comentarios en el 
microblog y resulta persuasivo por activar mucho más que el contenido expresado; es la matriz de la victoria declarada la que engendra la fuerza del eslogan político que vaticina la expulsión del kirchnerismo como opción de poder gubernamental.

En ese sentido, el imperativo para los militantes kirchneristas es contener la fuerza persuasiva del eslogan, aceptando el desafío de los contradictores a luchar en la arena virtual. El usuario@Silvineta1 lo interpela con la pregunta mordaz (No t enteraste??) y el anuncio de la inminente toma de investidura como senadora por parte de la expresidenta. De nuevo, se asume la voz colectiva (volvemos, nos vemos) para enfrentar el duelo a través de la réplica directa y aislando de su grupo al enemigo, con el tratamiento en segunda persona. La contrarréplica no es menos interesante: conservando el sarcasmo, (a) GonzaloLoyola devuelve el golpe condicionando el regreso al senado - ya no solo de la expresidenta, sino de todo el colectivo - al castigo judicial, implicado en la referencia a Ezeiza, el sector de Buenos Aires donde está la cárcel.

En este primer grupo de embates y duelos ejemplificados, el ataque a la honestidad, a través de la denuncia, se dirige a movilizar imputaciones legales contra la expresidenta, dentro del carácter más bien simplista e impune de los opiniones en los espacios virtuales. Es precisamente ese carácter el que autoriza la transformación de los espacios en arenas, toda vez que parece permitido luchar sin someterse a reglas muy estrictas y, sobre todo, estar exento de responsabilidades en la toma pública de la palabra.

\subsection{EL ATAQUE A LA DIGNIDAD, A TRAVÉS DEL INSULTO, PARA MOVILIZAR INDIGNACIONES}

\subsubsection{Embates}

En algunos embates contra la reputación, ejemplificados en el apartado anterior, había puesto entre paréntesis el uso de insultos para concentrarme en los recursos de la denuncia. En casos como los siguientes, los insultos aparecen más directamente ligados con los ataques contra la dignidad de la figura pública y las funciones de provocación:

\section{Figura 6. Embate 4}

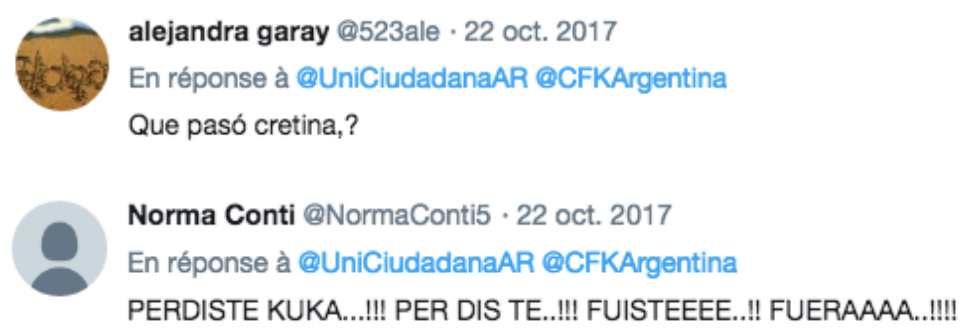

Las increpaciones descansan en los vocativos dispuestos dentro de intercambios oralizados, por los modos interpelativos directos y las modalidades interrogativa y exclamativa en estos tuits. Están, además, asociados con modos locales del insulto, que pueden hacerlos más herméticos para los participantes ajenos a las luchas. Son los casos de chorra, porota y kuka, y en menor medida, de cretina y psicópata. Los tres primeros utilizan argentinismos para ladrona, chismosa e idiota, aunque este último se utiliza más directamente contra el kirchnerismo y sus simpatizantes (UNTREF, 2018). Los disfemismos cretina y psicópata funcionan como insultos también por su carga cultural en la política argentina: el primero, como juego de paronomasia con el nombre de la expresidenta (Cristina/cretina); y el segundo, como activación de un incidente según el 
cual el Presidente recién electo la llamó psicópata, según el relato mediático difundido por una periodista y publicado en un libro basado en entrevistas, en mayo de 2017 (Di Marco, 2017). El ruido mediático de este relato era muy reciente todavía en el momento de las elecciones y los internautas oficialistas lo integraron recurrentemente en sus embates:

Figura 7. Embate 5

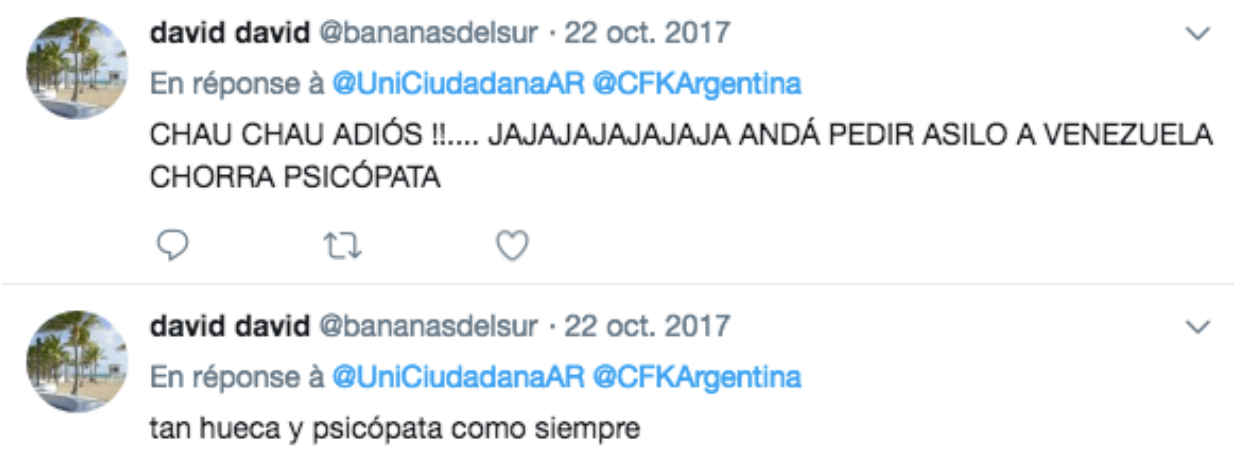

En este caso, el mismo usuario encadena dos embates contra la expresidenta, con una aparente gradualidad emocional del primero al segundo tuit, que se transparenta en el paso de la mayúscula sostenida a las minúsculas, la pérdida de las onomatopeyas y el cambio de actividad verbal en el segundo comentario. Si en el primero el insulto aparece dominado por la fuerza del imperativo, en el segundo la orden se convierte en una evaluación en forma de juicio y de apreciación negativa de la increpada. En términos del golpe verbal, sin embargo, la gradualidad no le resta fuerza al efecto de provocación movilizado por los insultos.

Más allá de sus funciones sociopragmáticas, a nivel de la descortesía (Fuentes, 2016; Kaul, 2014) y de sus efectos negativos para la deliberación pública (Bolívar, 2008), destaco aquí la dimensión erística del vituperio en los embates verbales: (i) es una forma de hostigamiento directo para desafiar al contendiente a involucrarse en la lucha; (ii) una instigación que profundiza la divergencia entre puntos de vista y mueve pasionalmente hacia las acciones de defensa y ataque; y (iii) una agresión que activa discursos anteriores contra la imagen del sujeto atacado (estereotipos, prejuicios, clichés, rumores, escándalos mediáticos, etc.), actualizando esas percepciones en función de la victoria en la arena. A estas oreintaciones del insulto en los microblogs sobre política, hay que añadir su aparición en interacciones entre militantes.

\subsubsection{Duelos}

En general, los duelos no son provocados en forma de afrentas iniciales y directas contra los usuarios, de manera espontánea, sino que aparecen como producto de las reacciones de los contradictores frente a las demostraciones de apoyo de los seguidores del líder. Así, los ataques contra la dignidad por vía del insulto son una expresión más o menos impetuosa de la cólera de los opositores que reclaman el reconocimiento de la derrota en el ideal democrático, por parte de la expresidenta: 


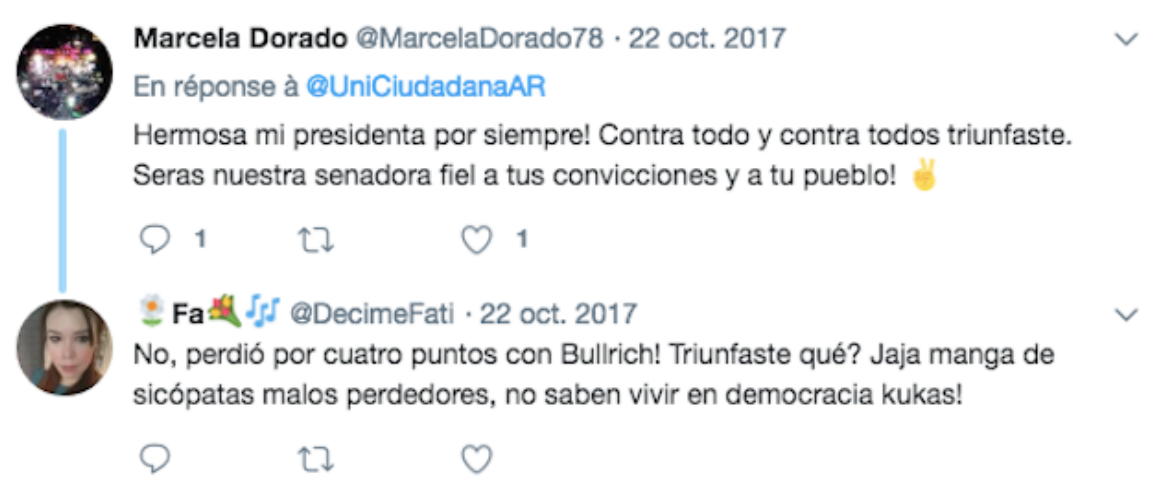

El tuit de@MarcelaDorado78 genera una provocación a través de la fuerte carga elogiosa (hermosa, fiel, perseverante, popular; etc.) que contribuye a reconstruir los resultados electorales en clave de victoria, con la declaración «triunfaste» y el refuerzo icónico del gesto victorioso ( $)$ ). El encomio inicia el duelo cuando engancha a la usuaria de la cuenta@DecimeFati, cuya reacción a esa reconstrucción discursiva avanza por medio del encadenamiento in crescendo de la reacción agresiva: negación categórica (No); aclaración cuantitativa (perdió por cuatro puntos...); pregunta desafiante (Triunfaste qué?); burla (jaja) e insultos (manga de sicópatas malos perdedores ...kukas). Es en estos encadenamientos progresivos donde quedan las huellas del desborde escalado de las pasiones; en ese orden escalar, los insultos suelen aparecer rematando las diversas acciones verbales conducidas por el entusiasmo. Pese a su brevedad, los tuits permiten ver ese escalamiento de las agresiones que resulta fácilmente reconocible en las disputas orales, aquí en formas condensadas, multimodales y oralizadas (aunque no necesariamente inmediatas, como se ve en las fechas del siguiente ejemplo):

Figura 9. Duelo 4

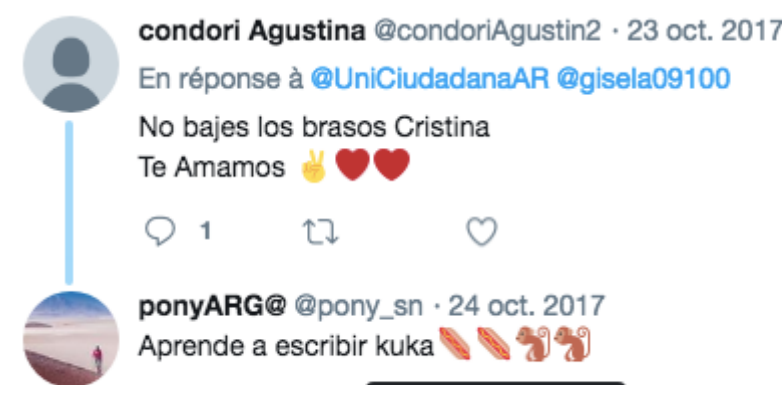

El mensaje de apoyo del militante kirchnerista también irrita al usuario de @pony_sn y motiva el insulto local ( $k u k a)$ acompañado de íconos con alguna carga ofensiva. En este caso, la reacción actualiza estereotipos en el orden de la incorrección ortográfica y el dominio de la cultura escrita. Aquí se trata de la vigilancia o del cuidado de la norma en las interacciones virtuales, pero orientada hacia la vituperación que no solo reprende, sino que fustiga al contendiente y cambia el foco del mensaje para el lector externo.

En los casos que ilustré antes, los duelos aparecen a partir de asedios de los antikirchneristas en el terreno de sus enemigos, en forma de respuesta a comentarios no erísticos entre los militantes y la expresidenta. Otros duelos, también en forma de asedios, se van a diferenciar por quedar posicionados en el punto de mira y ser objeto del ataque: 


\section{Figura 10. Duelo 5}

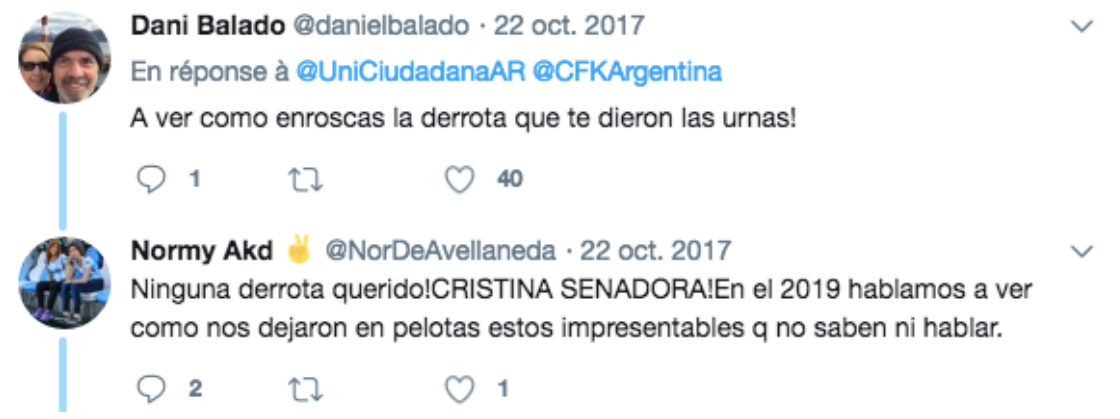

El cambio de posiciones, sin embargo, no altera sustancialmente los modos del ataque ahora liderado por los simpatizantes de la expresidenta: se niega la derrota y se avanza hacia el vituperio (estos impresentables que no saben ni hablar), formulado también como fustigación por el descuido de la norma en la conducta verbal. El punto de contacto entre acciones y reacciones verbales en estos duelos sigue girando en la órbita de la contradicción vencedores/vencidos en las elecciones legislativas. El usuario @danielbalado desafía a la expresidenta a eludir los resultados (enroscar la derrota) y la reacción de@NorDeAvellaneda enfatiza la interpretación de esos resultados como un triunfo (CRISTINA SENADORA!) complementado con el augurio, también bajo el signo del desafío (... a ver cómo...), que genera el evidente paralelismo en los tuits de este duelo.

En este segundo grupo de embates y duelos, se ilustró cómo los ataques a la reputación se concentraron en el uso de insultos contra la dignidad de la figura pública y de sus seguidores, para movilizar la indignación entre los simpatizantes del bando que se confronta. Si el análisis de los duelos opta por seguir la pista de los encadenamientos resultantes, las estructuras de las interacciones erísticas se complejizan tanto que su descripción puede tornarse engorrosa. Por esta razón y por los objetivos de este texto, se eligió mostrar solo el funcionamiento de duelos breves y dejar pendiente ese otro tipo de trabajo con los encadenamientos entre múltiples usuarios.

\section{CONCLUSIÓN}

En este artículo se propuso el análisis de un corpus de tuits publicados como reacción a una declaración audiovisual de la expresidenta argentina Fernández de Kirchner, por los resultados de las elecciones legislativas en octubre de 2017. Se destacó la dimensión erística de las interacciones en el microblog Twitter, a propósito de la presentación de esos resultados como victorias o como fracasos, y las luchas verbales que se concentraron en reclamar o en rechazar el reconocimiento de la derrota. En clave erística, el objetivo del análisis no fue resolver quién ganó realmente en esa competencia electoral, sino comprender qué significa que los actores declaren haber ganado, esto es, cuáles son los sentidos construidos acerca de las victorias en la arena política y cuáles son las formas de sus trofeos correspondientes.

En síntesis, las interacciones virtuales analizadas muestran cuatro características destacadas en este artículo: (1) un estilo dialógico confrontativo, a través del cual se adelantan disputas con niveles altos de agresividad y violencia verbal; (2) una destinación compleja, con tuits dirigidos tanto a los enunciadores de las cuentas xxxx, como a los internautas que participan a favor o en contra de esos enunciadores; y (3) una movilización amplia de recursos multimodales dirigidos hacia la generación de desconfianza en torno a una figura pública y a sus simpatizantes. 
En cuanto al primer rasgo, sobre el estilo, el dialogismo confrontativo anida en el principio de contradicción propio de las interacciones erísticas. No es posible pensar en esas relaciones sin referencia a los procedimientos interactivos entre los sujetos; sin embargo, no por ser interpersonales esas relaciones son transaccionales, pues ni el intercambio de ideas ni la transmisión de información están en su centro. Es en la dupla interdependiente acción-reacción donde los sujetos involucrados en estos combates virtuales encuentran afición a la lucha. Las diferencias entre las fuerzas involucradas son presentadas por sus agentes en términos constrastivos e, inclusive, dicotómicos. Las oposiciones no son inherentes a los sujetos que luchan, sino que son construidas por ellos, por terceros o por el ámbito de la disputa. Ese efecto de oposición está anclado en diferentes instancias: los medios, las estrategias o los sujetos mismos.

El problema de la destinación, por su parte, caracteriza a los intercambios agresivos en Twitter como interacciones complejas en las cuales los enunciadores pueden dirigirse, al mismo tiempo, a contrapartes particulares y generales. Esta multidestinación es posibilitada por las disposiciones de la plataforma virtual (espacios para respuesta directa, mensajes colectivos, etc.), pero también por la oportunidad de amplificar fácilmente la recepción y el daño de las agresiones, con relativa impunidad. Precisamente esta liberación de responsabilidades - a través del anonimato de las cuentas o del reclamo de los mensajes como libres opiniones - facilita el escalamiento de las interacciones agresivas en las redes virtuales, vistas así como medios para la catarsis o la liberación de emociones violentas.

En cuanto a la usual movilización de recursos audiovisuales y multimediales, como lo plantea Deuze (2006) a propósito de la cultura digital, se trata de una composición intencionada (montaje, desmontaje y reensamblado) altamente personalizada y, por tanto, impredecible. Los internautas hacen uso de los recursos disponibles en la web para atacar a sus oponentes, defenderse de las agresiones recibidas y profundizar sus posiciones políticas, a menudo a través de juegos con el humor, la burla o la ridiculización de las opiniones contrarias. A nivel del combate discursivo, la amplitud de estos recursos genera ventajas en la lucha, tanto por el cubrimiento de mayor espacio en la plataforma con imágenes, gifs, videos y demás, como por la mayor posibilidad de viralizar opiniones particulares a través del efecto de replicación de esas composiciones.

Esos rasgos destacados no solo están condicionados por el formato del microblog, sino que además son un producto de las lógicas bajo las cuales él mismo opera: interacciones entre varios participantes (o polílogos); anonimato o enmascaramiento de los participantes; ausencia casi total de moderación de opiniones; brevedad en los mensajes; y herramientas para su difusión masiva (Jackiewicz, 2016; Zappavigna, 2012).

La caracterización de estas interacciones virtuales como discursos erísticos permitió entender que el reclamo de la victoria en esa contienda electoral implicó también reclamarle a los contradictores que reconocieran haber perdido rotundamente. Para el oficialismo, ese reconocimiento resultaba fundamental a favor de la continuidad de su estrategia política de extensión sobre la nación desde el dominio de la zona capital y para reafirmar la estabilidad del gobierno macrista basándola en la polarización con el kirchnerismo, presentado como un punto de no retorno y una herencia deleznable. Por su parte, para la estrategia de la expresidenta y de su partido, aun al no haber obtenido mayorías electorales, su llegada al parlamento no podría significar una derrota sino un lugar de liderazgo de la oposición al oficialismo. Con la conciencia de esa nueva tribuna, los militantes kirchneristas continuaron reforzando la movilización social y el activismo contencioso como soporte de la legitimidad política de ese colectivo (Mauro, 2018: 127); una relación que fue construida a lo largo de los gobiernos Kirchner (2001-2015) y que 
migró sin dificultades a la esfera virtual, donde encontró aun más posibilidades para la lucha verbal.

Los resultados de esas elecciones legislativas llevaron, entonces, a reclamar las victorias para humillar a los vencidos; sus gestores irrumpieron con la fuerza de la vergüenza reclamada, en los espacios virtuales colonizados por los militantes kirchneristas. En el texto, se desmontaron los mecanismos de esas acciones de fuerza, diferenciándolas según su destinatario directo en embates (respuestas a la expresidenta) y duelos (respuestas entre los internautas). Ambos tipos de destinación confluyeron en movimientos de ataque, entre los cuales se destacan: 1) el uso de la denuncia para atacar la honestidad y movilizar sospechas; y 2) el uso del insulto para atacar la dignidad y movilizar la indignación.

Se ilustraron esas movidas con ejemplos de embates y duelos que permitieron expandir o mirar más en detalle la complejidad de esos mecanismos, especialmente cuando involucran bricolajes con una riqueza de recursos que son inagotables para el analista. En el sentido de esta limitación, se prefirió mostrar la lógica de esos movimientos y sus implicaciones en el nivel sociopolítico, por lo cual se propuso reunirlas en recursos de la agresión, ataques contra la reputación y efectos sobre la movilización de vergüenza pública; la relación instrumental entre estas categorías amenaza la fides entre representantes y representados; profundiza la lucha política polarizada (agonisticus); y puede poner en riesgo la auctóritas de los líderes en el espacio público. Se propuso, entonces, inscribir estos embates y duelos en el campo de las pruebas por el ethos, por el logos y por el pathos, respectivamente.

En todos los casos, se habló de combates y no de debates, es decir, de interacciones erísticas. En este artículo se sostiene que es dudoso que haya debates en Twitter o en espacios virtuales que les sean análogos. Hay embates y duelos, en el caso abordado, para radicalizar la postura o la opinión al respecto de una figura pública protagonista en la historia de la política argentina. Ninguno de los embates fue replicado por la expresidenta, pues los políticos no se muestran particularmente interesados en debatir a través de Twitter. Al contrario, esa plataforma les sirve para sobreexponerse de manera relativamente segura y sin comprometerse con interacciones argumentativas ni con rendiciones de cuentas. Los duelos, en cambio, generaron hilos complejos de intercambios que progresaban en animosidad e iban profundizando en su desarrollo la disputa y la discordia entre las posiciones presentadas. En el caso analizado, la clave de esa radicalización fue la declaración de haber ganado las elecciones legislativas, por parte de cada bando.

Si bien se ha pensado en las plataformas virtuales como herramientas de polarización social, esa polarización precede al uso de la herramienta y, por tanto, esta última no es causa de aquella. La radicalización es un fenómeno distinto, confirmatorio, que sí encontraría una posible causa - aunque no exclusiva - en el uso de estas plataformas. En los procesos de radicalización, esos espacios resultan más efectivos que las plataformas informativas (como los sitios web), pues en estas últimas los militantes no se involucran más que como espectadores de posiciones políticas, mientras que en los segundos (blogs, foros de discusión, espacios de comentarios del lector, etc.) asumen el poder de levantar su voz con tanta estridencia como son capaces de hacerlo.

Finalmente, no es tan claro cómo juzgar el daño efectivo de estos ataques, más allá de mediciones estadísticas de tendencia y redifusión de tuits, desde donde se desarrolla una amplitud de trabajos (Lutz \& Du Toit, 2014; Zappavigna, 2012) que, en realidad, pueden explicar los usos de las redes sociales, pero no necesariamente las conductas políticas de los sujetos por fuera de esas redes. Twitter se presenta, así, como un sensor de cambios en la atención a tópicos sobre lo político y a combates virtuales en 
torno a sus temas, pero no es una herramienta de observación de lo político en sí mismo. Mucho menos es un ágora polifónica de discusiones (ni elaboradas ni superficiales) sobre los temas de interés público, pues las reglas del debate suelen quedar desplazadas por los imperativos del combate.

No es extraño que esos imperativos dominaran en la coyuntura política argentina del año 2017. Si se asume que una de las características de la izquierda suramericana ha sido el hiperpresidencialismo (Malamud, 2016b: 61), la activa presencia - aunque no responsiva - de Fernández de Kirchner en Twitter contribuyó a reemplazar la afiliación a las ideas políticas por la afiliación a la persona. En estos proyectos progresistas, la personalización ha conducido a la paradoja de requerir líderes fuertes con alto poder de convocatoria, pero no poder pensar tales proyectos más allá de los límites de esos mismos líderes. En este sentido, los militantes en pugna reclamaron la victoria y rechazaron la derrota electoral como parte de una victoria más grande, por venir: la de retener o recuperar - para cada bando - la silla presidencial. Una de las tareas pendientes de la izquierda latinoamericana tiene que ver con el replanteamiento de esta concepción del liderazgo; sus militantes podrían dejar de luchar en nombre de alguien, para pasar a luchar en nombre de algo. No obstante, un progresismo consciente también deberá contar con que el desborde de las pasiones y los combates en las arenas reales y virtuales seguirán siendo determinantes para la decisión de los rumbos que tomen los países en cada elección popular.

\section{REFERENCIAS BIBLIOGRÁFICAS}

Alimi, Eitan, Chares Demetriou y Lorenzo Bosi. 2015. The dynamics of Radicalization. Oxford: Oxford University Press.

Amossy, Ruth. 2014. Apologie de la polémique. París: PUF.

Arnoux, Elvira. 2006. Análisis del Discurso. Buenos Aires: Santiago Arcos.

Boix, Andrés. 2016. «La construcción de los límites a la libertad de expresión en las redes sociales». Revista de Estudios Políticos, 173: 55-112. doi: http://dx.doi.org/10.18042/cepc/rep.173.02

Bolívar, Adriana. 2008. «Cachorro del imperio versus 'Cachorro de Fidel': los insultos en la política latinoamericana». Discurso \& Sociedad, 2(1): 1-38.

Borum, Randy. 2011. «Radicalization into Violent Extremism I: A Review of Social Science Theories». Journal of Strategic Security, 4(4): 7-36. doi: http://dx.doi.org/10.5038/1944-0472.4.4.1

Calvo, Ernesto. 2015. Anatomía política de Twitter en Argentina. Buenos Aires: Capital Intelectual.

Campos-Domínguez, Eva. 2017. «Twitter y la comunicación política». El profesional de la información, 26(5): 785-793.

Clausewitz, Clause. 2005[1832]. De la guerra. Madrid: La Esfera de los Libros.

CNN. 2017, noviembre 9. «QQué acusaciones enfrenta Cristina Fernández de Kirchner?» http://cnnespanol.cnn.com/video/cnnee-pkg-ivan-perez-sarmenti-queacusaciones-enfrenta-cristina-fernandez-argentina/

Crystal, David. 2004. Language and the Internet. Cambridge: Cambridge University Press.

Deuze, Mark. (2006). «Participation, remediation, bricolaje». The Information Society, $22(2), 63-75$. 
Di Marco, Laura. 2017. Macri: historia íntima y secreta de la élite argentina que llegó al poder. Buenos Aires: Penguin Random House.

DNE (Dirección Nacional Electoral). 2017. «Resultados de las elecciones legislativas 2017». http://www.resultados.gob.ar/inicio.htm

Farah, Douglas. 2014, mayo 5. «El extraño caso de Lázaro Báez». Univisión Noticias. https://www.univision.com/noticias/noticias-de-latinoamerica/el-extrano-casode-lazaro-baez

Fuentes, Carolina. 2016. «(Des)cortesía, imagen social e identidad como categorías sociopragmáticas en el discurso público». En Roles situacionales, interculturalidad y multiculturalidad en encuentros en español, eds. Domnita Dumitrescu y Diana Bravo. Buenos Aires: Dunken, 165-192.

Gil, Marta. 2013. «Sobre el sentimiento de vergüenza en la Ética Nicomaquea y la Retórica de Aristóteles». Revista Internacional de Filosofía, 58: 5-18.

Himelboim, Itai, Stephen McCreery y Marc Smith. 2013. «Birds of a feather tweet together». Journal of Computer-mediated Communication, 18(2): 40-60.

Jackiewicz, Agata. 2016. «Reprises et détourments polémiques sur Twitter». Travaux de linguistique, 73: 85-105.

Jackiewicz, Agata. 2017. «Outils notionnels pour l'analyse des controverses». Questions de Communication, 31: 137-159.

Kaul, Silvia. 2014. «La descortesía verbal en el contexto político ideológico de las redes sociales». Revista de Filología, 32: 154-162.

Lutz, B. \& du Toit, P. (2014). Defining Democracy in a Digital Age. New York: Palgrave MacMillan.

Maireder, Axel y Julian Ausserhofer. 2014. «Political Discourses on Twitter». En Twitter and Society, eds. Katrin Weller, Axel Bruns, Jean Burgess, Merja Mahrt y Cornelius Pushmann. New York: Peter Lang, 305-318.

Malamud, Andrés. 2016a. «La izquierda argentina». Foreign Affairs Latinoamérica, 16(3): 21-27.

Malamud, Andrés. 2016b. «¿Por qué retrocede la izquierda en América Latina?». En ¿Por qué retrocede la izquierda?, eds. Marcelo Leiras, Andrés Malamud y Pablos Stefanoni. Ciudad Autónoma de Buenos Aires: Capital Intelectual, 47-80.

Malamud, Andrés y De Luca, Miguel. 2016. «¿Todo sigue igual que ayer? Continuidad y ruptura en el sistema de partidos argentino (1983-2015)». En Los sistemas de partidos en América Latina, 1978-2015, ed. Flavia Freindenberg. México: UNAM/INE, 27-68.

Mauro, Sebastián. 2018. «Representation, Party System, and Civil Society in Argentina (2003-2015)». En Civil Society and Political Representation in Latin America (2010-2015), ed. Adrián Albala. São Paulo: Springer, 117-130.

Olave, Giohanny. 2019. «Una perspectiva erística para el estudio de disputas verbales públicas». En Estudios de la Maestría en Lingüística, comp. Mireya Cisneros. Pereira: UTP, 33-56.

Ramírez Vidal, Gerardo. 2018. «La pistis-fides como el objeto propio de la retórica». Quadripartita Ratio, 3(5): 37-48.

Racionero, Quintín. 1999. «Introducción». En Retórica, Aristóteles. Madrid: Gredos. 
UNTREF. 2018. Diccionario Latinoamericano de la Lengua Española. http://untref.edu.ar/diccionario/diccionario.php

Vommaro, Gabriel y Mariana Gené. 2017. «Argentina: el año de Cambiemos». Revista de ciencia Política, 37(2): 231-253.

Yasri, Éleonore. 2016. «Discours identitaires et investissement émotionnel». Cahiers de praxématique, 66 . http://praxematique.revues.org/4299

Zappavigna, Michele. 2012. Discourse of Twitter and Social Media. Londres: Continuum. 